\title{
O ENSINO DE SOCIOLOGIA E OS SEUS PÚBLICOS
}

\author{
FAgner CARniel $^{1}$ \\ Zuleika de Paula Bueno ${ }^{1}$
}

\begin{abstract}
RESUMO: O artigo problematiza o engajamento da sociologia brasileira com audiências não acadêmicas, sinalizando o papel estratégico que o ensino escolar desempenha na construção das dimensóes públicas dessa área do saber. Desse modo, a secundarização dos conhecimentos sociológicos e as preocupaçóes intelectuais com a sua divulgação são analisadas ao longo do texto, em meio às disputas e tensóes enfrentadas durante o retorno da disciplina aos currículos da educação básica.
\end{abstract}

Palavras-chave: Sociologia. Sociologia Pública. Educação Básica. Ensino. Currículo.

\section{THE TEACHING OF SOCIOLOGY AND ITS AUDIENCE}

ABSTRACT: The article problematizes the engagement of Brazilian sociology with non-academic audiences, signaling the strategic role that school education plays in public aspects construction in this area of knowledge. Thus, the downgrading of sociological knowledge and intellectual concerns with its dissemination amidst disputes and tensions faced during the return to the basic education curricula are analyzed throughout the text.

Keywords: Sociology. Public Sociology. Basic education. Teaching. Curriculum.

\section{L'ENSEIGNEMENT DE LA SOCIOLOGIE ET SES AUDIENCES}

Résumé: Cette article problématise l'engagement de la sociologie brésilienne devant l'audience non-académique, en signalant le rôle stratégique que l'éducation scolaire joue dans la construction des dimensions publiques de ce domaine du savoir. De cette façon, la subordination des connaissances sociologiques et la préoccupation des intellectuelles avec sa diffusion sont analysées dans ce texte au milieu des disputes et tensions rencontrées alors que la discipline était replacée aux programmes d'éducation de base.

Mots-clés: Sociologie. Audiences. Éducation de base. L'enseignement. Curriculum.

${ }^{1}$ Universidade Estadual de Maringá, Programa de Pós-Graduação em Ciências Sociais - Maringá (PR), Brasil. E-mails: fagnercarniel@yahoo.com.br; zubueno@hotmail.com

DOI: 10.1590/ES0101-73302018186181 


\section{Introdução}

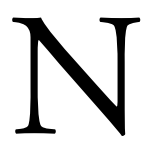

o dia 9 de março de 2016, a assessoria de comunicação do Ministério Público Federal do estado do Mato Grasso noticiou a instauração de um inquérito civil com as finalidades de reunir informaçóes do Ministério da Educação (MEC) e fiscalizar a qualidade dos livros didáticos avaliados e recomendados pelo Programa Nacional do Livro e do Material Didático (PNLD) para a educação básica brasileira. $\mathrm{O}$ documento fundamentou-se nas interpretaçóes divulgadas em um artigo de opinião publicado pela revista Época em 29 de fevereiro de 2016. Nesse texto, o professor Fernando Luiz Schüler foi enfático ao afirmar que havia um direcionamento político, especificamente nos materiais didáticos das disciplinas de humanidades, que comprometia o "pluralismo teórico" esperado para o ensino escolar e legitimava a "doutrinação ideológica” nas salas de aula.

A repercussão do texto gerou uma enxurrada de manifestaçóes contrárias e favoráveis que circularam pelas mídias sociais ativando a participação de intelectuais, docentes, estudantes, familiares, entidades científicas, partidos políticos, sindicatos e diversos coletivos da área em torno da defesa ou da contestação da "autonomia pedagógica".

Produzido em um momento de acirramento dos conflitos político-partidários que levaram ao golpe parlamentar no governo da então presidenta Dilma Rousseff, esse episódio polêmico esteve articulado a debates mais amplos que reintroduzem a questão dos significados públicos da escolarização no país.

Ao longo da última década, inúmeras disputas curriculares politizaram o campo educacional e impactaram decisivamente na vida escolar. Entre os pontos de controvérsia, destaque particular pode ser conferido à introduçáo de pautas pertinentes à diversidade étnico-racial e religiosa, aos direitos humanos, às relaçóes de gênero e sexualidade, às formas de inclusão, à formação de jovens e adultos, à educação no campo, indígena e quilombola, ou mesmo às tecnologias da informação e da comunicação. Esses são apenas alguns exemplos de temáticas ou de políticas recentes que tensionaram as práticas de ensino brasileiras no início do século XXI. Em meio às discussões suscitadas pela postulação dessas questões, o próprio retorno das disciplinas de Sociologia e de Filosofia para o ensino médio converteu-se em um foco de conflitos (MORAES, 2014).

No que se refere à disciplina de Sociologia, o engajamento histórico com a análise da realidade nacional, bem como a interlocução imediata de seus conteúdos com a compreensão do tempo presente, tem criado espaços de formação potencialmente incômodos para quem se sente criticado, desafiado ou desautorizado em suas perspectivas sociais. Além disso, a constituição plural desse corpo de conhecimentos, aliada à certa incompreensão quanto ao rigor e à objetividade de seus métodos heterogêneos de análise, produz frequentes desentendimentos sobre o valor ou a legitimidade da sociologia na educação básica. 
Nesse sentido, não chega a ser surpreendente a existência de tantos entraves institucionais para consolidar o lugar da sociologia nos currículos escolares (SILVA, 2014). Curiosamente, a acusaçáo de que hoje a disciplina desempenharia papel meramente ideológico nas escolas surge em um momento de fortalecimento das ciências sociais como especialidade, tanto entre as elites intelectuais (HEY \& RODRIGUES, 2017) quanto entre os próprios agentes do ensino médio (SANTOS, 2017). Uma parcela considerável das atuais pesquisas sobre o ensino de sociologia ressalta o papel decisivo que a disciplina pode exercer na construção de uma educação científica entre as humanidades (HANDFAS, 2014).

De fato, para as ciências sociais, a educação formal representa um dos caminhos prioritários de divulgação do conhecimento especializado. É nas salas de aula que a maior parte das pesquisas e das teorias produzidas no país consegue circular e, em alguma medida, impactar a vida social. Um espaço, aliás, que confere não "utilidade", mas materialidades diversas para ideias, categorias e enunciados fabricados no interior daquilo que Michel Foucault (2010) denomina de "economia política da verdade". Para a sociologia brasileira, particularmente, o ambiente escolar também foi locus primordial de trabalho intelectual e de rotinização das primeiras concepçóes acerca da possibilidade de um estudo científico da sociedade (MEUCCI, 2014). Por meio dele, o próprio campo acadêmico das ciências sociais pôde se estruturar ao longo do século XX, consolidando uma forma de cultura científica que se tornaria cada vez mais central no estabelecimento da democracia e na construção de mecanismos para a efetivação da cidadania (MARQUES, 2008). O que explicaria, então, o fato de a divulgação e de o ensino de nossos saberes ainda serem táo conturbados nas redes públicas e privadas do ensino médio?

As sucessivas críticas ou resistências que o ensino de sociologia acumula na entrada deste novo milênio sinalizam tanto o caráter instável da disciplina nos currículos escolares quanto a desconfiança com que diferentes setores da população recebem os conhecimentos produzidos pelas universidades e centros de pesquisa do país. Essas reaçóes contrárias seriam fruto da mera incompreensão de uma sociedade elitista, conservadora e com baixos índices de escolaridade? Ou, inversamente, deveríamos acreditar que a natureza complexa das teorias sociais estaria dificultando o conhecimento sociológico de habitar outros espaços que não aqueles em que foram originalmente desenvolvidos? Em vez de reificar estereótipos que polarizam o saber em formas leigas e especializadas, talvez possamos encontrar outra maneira de encarar esse problema se voltarmos a verificar o modo como a sociologia tem participado da construção de uma cultura científica compartilhada. Afinal, ao menos desde que Florestan Fernandes (1955, p. 14) chamou a atenção para a urgência em "conquistar os coraçōes e as mentes dos jovens para as carreiras científicas", o pensamento social brasileiro parece ter sido convocado para refletir sobre as suas inúmeras possibilidades de disseminação. 
Neste texto, abordamos o engajamento da sociologia com suas audiências não acadêmicas por meio do debate em torno das dimensóes públicas do conhecimento sociológico. Particularmente, interessa argumentar que a sociologia escolar tem desempenhado papel decisivo na publicização dos saberes sociológicos no Brasil. Para isso, apontamos, no tópico seguinte, alguns processos sociais que concorrem para a secundarização dos conhecimentos sociológicos no imaginário social e acadêmico brasileiro, bem como o ressurgimento de uma preocupação intelectual com as formas de divulgação das pesquisas produzidas pela área. Em seguida, analisamos o papel determinante que os diferentes projetos educacionais e políticos desempenharam na rotinização de diferentes concepçóes de sociologia ao longo do século XX. Narramos, assim, um processo de conflitos e de tensóes que se desenha em torno das instituiçóes escolares e das disputas por projetos concorrentes de sociedade. Trata-se, portanto, de uma disputa por espaço de atuação, legitimidade e formação no que se refere aos próprios públicos com os quais queremos dialogar.

\section{Praticamos uma ciência pública?}

Atualmente, já não causa espanto afirmar que os discursos científicos estão enraizados de modo inexorável na constituiçáo do mundo em que vivemos. Mesmo atividades corriqueiras como observar as coisas ao nosso redor e falar sobre elas são, hoje, absolutamente influenciadas pelas diferentes gramáticas normativas apresentadas pelas ciências modernas. Mais do que maneiras de nomear as entidades e explicar os fenômenos que ocorrem na vida social ou natural, o que esses conhecimentos oferecem são as próprias perspectivas culturais pelas quais muitos de nós aprendemos a imaginar, produzir e habitar o planeta.

Tamanha centralidade do pensamento científico em nosso imaginário, no entanto, não ocorreu de uma hora para outra. Como explica Ana Delicado (2004, p. 4), açóes e espaços destinados ao que se convencionou chamar de "educação científica" datam de pelo menos um século e estão relacionados à ideia de criar formas de "comunicação entre o campo de produção da ciência e a esfera pública”, difundindo termos, procedimentos e postulados. Nesse sentido, parece relevante indagar: a sociologia participa das percepçóes e da imaginação social sobre a ciência? Em que medida os saberes desenvolvidos pela área se apresentam como pertinentes para a divulgação científica?

Estudiosa dos processos de popularização das ciências, Delicado (2004) destaca a percepção desfavorável dos meios científicos euroamericanos dos séculos XX e XXI no que tange às investigaçóes sociológicas e sua restrita participação nos espaços destinados à disseminação das ciências, como museus, instituiçóes de ensino ou periódicos de divulgação. Conforme a autora, se a falta de informaçôes básicas sobre física, química, biologia ou matemática é vista com grande preocupação pelas agências promotoras de açóes de difusão e de ensino, 
o mesmo não acontece em relação ao desconhecimento dos saberes sociológicos. A posição da sociologia no interior da cultura científica dominante não é ignorada pelos profissionais da área. O estatuto epistemológico plural e antipositivista das teorias sociais historicamente tem dificultado o diálogo com outros campos de produção do saber, como aqueles vinculados às ciências exatas, cognitivas ou naturais. Essa situação, a exemplo do que já observou Pierre Bourdieu (2004) ao analisar o contexto francês, reflete em alguma medida a posição geralmente ocupada pela disciplina e por seus principais representantes na hierarquia das relaçóes acadêmicas, corroborando para fragilizar as percepçóes públicas acerca da "cientificidade" das pesquisas desenvolvidas. Desse modo, tais formas de "distinção" no universo das ciências modernas não apenas enfraquecem o papel do conhecimento sociológico no conjunto das atividades acadêmicas, como também impactam profundamente o lugar que a sociologia ocupa nos processos de divulgação e de educação científica.

Por outro lado, a falta de reconhecimento acadêmico da sociologia parece explicar apenas em parte o aparente desinteresse social por seus conhecimentos. Se assim fosse, outras disciplinas com corpus teóricos e metodologias bem menos consolidados do que a Sociologia — tais como o Direito, o Jornalismo, a Economia, a Psicologia ou a Administração — também encontrariam dificuldades em popularizar-se. Por meio de um levantamento empírico sobre o estado atual da sociologia na imprensa norte-americana, Catherine Siebel e Katherine Smith (2009, p. 292) confirmam a restrita inserção desses estudos no diálogo com públicos mais amplos. Elas revelam que, mesmo quando a sociologia se faz presente nesses veículos, seus conteúdos costumam ser expressos em "depoimentos sobre experiências de pesquisa” que pouco lembram os discursos originais. Nesse sentido, Siebel e Smith (2009) propóem uma inversão interessante do problema. No lugar de perguntar pela cientificidade, as autoras indagam acerca do quanto somos públicos; ou melhor, a respeito do quanto participamos da agenda pública das ciências.

No Brasil, os pesquisadores da área enfrentam desafios semelhantes ou, talvez, ainda mais profundos do que aqueles encontrados em contextos europeus ou norte-americanos, pois a "vocação pública" de seus trabalhos parece ter convivido com diferentes formas de elitismo acadêmico ao longo do século XX. Desse modo, diversos trabalhos que atualmente vêm recuperando a história da sociologia brasileira (REIS; REIS; VELHO, 1997; KEINERT \& SILVA, 2010; PERLATTO, 2016) demonstram como a sua consolidação não ocorreu desvinculada da atuação de seus representantes na vida pública e na participação em movimentos sociais, quadros da burocracia estatal, partidos políticos e no debate ativo por propostas de modernização da sociedade. Tais formas de engajamento com públicos e finalidades diversos, entretanto, parecem ter dependido dos fortes vínculos com os meios universitários e, particularmente, com os programas de pósgraduação, enquanto locus de legitimação científica das elites intelectuais do país. 
Esse processo resultou na desvalorização simbólica de outros agentes e em outras formas de atuação profissional, como a docência na educação básica. Assim, a participação da sociologia na construçáo de uma agenda pública das ciências acabou valorizando, principalmente, as esferas dominantes de poder, articulando-se com a formulação de políticas de impacto macrossocial que estiveram afastadas tanto dos processos públicos de divulgação quanto da educação escolar. Por isso mesmo, intelectuais da área como Lívia Pires de Moraes (2016) afirmam que a divulgação dos saberes construídos por meio dos parâmetros científicos do campo sociológico vem ocorrendo hegemonicamente no interior da própria comunidade científica, o que historicamente valoriza a circulação restrita dos saberes e confere legitimidade para a construção das perspectivas sociológicas. Todavia, há quebras ou descontinuidades no interior dessa lógica de fechamento acadêmico do conhecimento sociológico. Uma delas aconteceu em meados da década de 1990, com a emergência de debates quanto à obrigatoriedade do ensino de Sociologia nos currículos escolares do país. Tais debates foram conduzidos, em grande parte, por professores universitários que se articulam na luta por um objeto científico específico - o ensino de Sociologia — e na inserção de cientistas sociais nos espaços de formulação e execução das políticas educacionais.

Diante desse cenário, seria estranho que a sociologia se tornasse uma especialidade largamente reconhecida e prestigiada em outros lugares que não aqueles ocupados pelos próprios cientistas sociais. Ainda assim, ela pôde se disseminar de maneira expressiva nas últimas décadas — um fenômeno que se materializou na abertura de novos postos de trabalho, na ampliação de sua penetração nos meios midiáticos e, sobretudo, no retorno do ensino de Sociologia aos currículos escolares. Tudo isso contribuiu para a circulação das ideias produzidas cuja abrangência não se imagina em outros períodos de sua história. Um exemplo emblemático desse processo foi a repercussão do Exame Nacional do Ensino Médio (Enem) de 2015, principal avaliação para o ingresso no ensino superior do país. Com o tema "a persistência da violência contra a mulher na sociedade brasileira", a redação daquele ano colocou em evidência categorias, debates e perspectivas usualmente ativados por pesquisas sociológicas sobre desigualdades de gênero e sexualidade, balançando a invisibilidade histórica dessas formas de violência na escola.

Esse tipo de engajamento público da sociologia brasileira, contudo, ainda parece ser incipiente se comparado à disseminação das produçóes acadêmicas de outras áreas, como é o caso daquelas vinculadas às biociências (LUZ et al., 2013). Para isso, os meios de comunicação desempenham papel importante, explorando o consumo generalizado de "descobertas" genéticas, neurológicas e médicas e negligenciando o desenvolvimento de pesquisas sociais. Por outro lado, a existência de uma ampla rede de trabalho destinada à divulgação e à educação "em ciências" também parece corroborar para a construção de certos saberes enquanto normatividades dominantes (LUZ; SABINO; MATTOS, 2013). 
No Brasil, em 2015, os resultados de uma investigação sobre a percepção pública da ciência e da tecnologia encomendada pelo entáo Ministério da Ciência, Tecnologia, Inovaçóes e Comunicaçóes indicavam que diversos setores da sociedade demonstravam interesse por assuntos relacionados à ciência e tecnologia e confiança nos benefícios produzidos pelos desenvolvimentos científicos. Ao indagar sobre temas científicos de preocupação dos entrevistados, a pesquisa destacou aqueles referentes às plantas transgênicas, à energia nuclear, ao uso de pesticidas na agricultura, às mudanças climáticas e ao desmatamento na Amazônia. Embora seja evidente que esses temas são objetos centrais não apenas das biociências, mas também das humanidades, resta indagar o quanto da participação das ciências sociais na discussão desses temas é percebido publicamente.

A não percepção de tais questôes como campo de atuação das ciências sociais limita tanto o impacto das perspectivas sociológicas como subtrai grande parte de seu potencial transformador da ordem social. Essa preocupação, aliás, não é nova nas ciências sociais do país. No discurso de abertura do II Congresso Brasileiro de Sociologia, em 1962, Florestan Fernandes (1986, p. 76) já apontava as dificuldades de comunicação dos sociólogos com o grande público, salientando a necessidade de se criar canais sociais capazes de traduzir o conhecimento especializado em "técnicas sociais racionais" que contribuíssem para a mudança social.

Uma das formas pelas quais essa questão começou a ressurgir no campo acadêmico brasileiro, quase meio século depois das advertências de Fernandes, está ligada à tentativa de se construir uma dimensão "pública" para a prática sociológica (ALMEIDA, 2007; BRAGA, 2009; SCHWARTZMAN, 2009; MELLO, 2009; PERLATTO, 2010; PERLATTO \& MAIA, 2012).

A expressão sociologia pública adquiriu destaque quando o sociólogo norte-americano Michael Burawoy (2009) a empregou em sua conferência presidencial, no encontro da Associação Americana de Sociologia (ASA) de 2004. Nessa conferência, o estudioso lançou um apelo pelo engajamento dos profissionais da área com a "retradução" das pesquisas sociológicas, "devolvendo o conhecimento àqueles de onde tal conhecimento veio" (BURAWOY, 2009, p. 19). Nessa proposta a prática da sociologia profissional, de caráter instrumental e acadêmico, se combinaria com a sua face pública, reflexiva e extra-acadêmica, exigindo dos pesquisadores o compromisso ético com os usos e as recepçóes de suas pesquisas.

Um aspecto relevante de ser debatido na proposta de Burawoy (2009) diz respeito a quantos públicos existem em sua concepção de sociologia pública. Uma primeira noção de público refere-se ao engajamento da sociologia no diálogo com todos aqueles que se colocam como interlocutores externos ao campo científico. Esse diálogo constitui a prática de sociologia pública tradicional, aquela que se destina à exposição dos resultados e das reflexôes da sociologia profissional a uma audiência não especializada e que geralmente se materializa na produçáo 
de livros, debates, entrevistas ou artigos direcionados ao público considerado pelo campo científico sociológico como leigo.

Outra concepção que se articula à sociologia pública, mas que também a modifica, diz respeito ao que Burawoy (2009) classifica como "sociologia pública orgânica". Trata-se daquela na qual "o sociólogo trabalha em íntima conexão com determinado público visível, denso, ativo, localizado e frequentemente contraposto" (BURAWOY, 2009, p. 26). As audiências, nesse caso, não estão apenas interessadas em compreender a sua situação, mas comumente reivindicam do intelectual público colocaçóes políticas em favor das lutas ou dos coletivos que representam. Nesse sentido, a noção de público aqui se refere ao relacionamento da sociologia com a vida política e à capacidade de a sociologia influenciar e transformar o mundo da vida.

A proposição de Burawoy não foi recebida sem oposições ou controvérsias (BECK, 2010; TURNER, 2009). A despeito disso, o impacto de suas reflexôes reintroduziu na agenda sociológica do século XXI debates que perpassam o pensamento social clássico e contemporâneo e ativam sentidos éticos e formativos da disciplina na fabricação de novos modos de perceber e atuar no mundo em que vivemos. Nessa direção, o autor tem direcionado seus esforços mais recentes para postular a necessidade de uma "sociologia pública internacional" capaz de lidar com os desafios globais que as sociologias nacionais já não conseguem responder - particularmente aqueles acerca do fortalecimento das cidadanias e do enfrentamento das desigualdades. Tal "sociologia global", defendida recentemente por Burawoy $(2010 ; 2016)$, encontraria, nas manifestaçóes públicas da área, maneiras de criar interconexōes significativas entre a pluralidade de sociologias "críticas", "políticas" e "profissionais" e a diversidade de seus públicos.

Assim, o trabalho de publicizar conhecimentos sociológicos, em seu ponto de vista, não se relacionaria apenas com a tradução e divulgação desses saberes. Ele também ofereceria elementos pertinentes para a formulaçáo de novas explicaçóes, ao mesmo tempo objetivas e engajadas, cosmopolitas e provincianas, acerca dos efeitos gerados pela radicalização dos processos de mercantilização e de regulação do social em uma escala planetária. Ao dar continuidade a esse ambicioso projeto intelectual, Burawoy (2014) vem debruçando-se sobre os sentidos da sociologia pública nos mais diversos contextos nacionais e sobre o modo como assumem a perspectiva da sociedade civil e dos coletivos que a conformam.

\section{A sociologia nos currículos da educação básica brasileira}

O modo como determinadas ideias, categorias ou perspectivas sociológicas circulam socialmente, habitando lugares extra-acadêmicos de produção do conhecimento, representa atualmente um eixo significativo dos estudos sobre o pensamento social brasileiro. Nesse cenário investigativo, não adquirem destaque 
apenas as maneiras pelas quais atitudes intelectuais identificadas com o pensamento sociológico se enraízam no cotidiano ou se materializam em produçóes culturais. Entra em discussão também o próprio papel das diferentes instituiçóes na produção das variadas cotidianidades que concorrem para sustentar e expressar certo corpus nacional da sociologia. Tais instituiçóes, para utilizar uma expressáo de Raymond Williams (1979), seriam corresponsáveis por "amarrar” as ideias, inclusive as científicas, em comunidades de práticas que, por meio de suas disputas e de seus interesses particulares, ajudam a lhes conferir forma e substância.

Depois de um largo período de constrangedor silêncio acadêmico, formou-se no país um repertório relativamente denso de pesquisas que recuperam o papel da educação básica no processo de constituição das ciências sociais (HANDFAS, 2011). Em linhas gerais, tais pesquisas sinalizam a relevância de considerar a sociologia escolar como uma instância legítima e potencialmente efetiva de criação, de difusão e de rotinização das ideias sociológicas entre setores da sociedade que não estão necessariamente em contato com o que é produzido nas universidades. Trata-se, de fato, de um processo de recontextualização do formato acadêmico desse saber especializado, que tem lhe conferido outros modos de existência, com eficácias diferenciadas ao longo do tempo.

Desse modo, a dimensão curricular do ensino de sociologia, bem como seus usos, sentidos e aplicaçóes, converteu-se em um objeto de interesse e de reflexão contemporânea. Em uma série histórica, as pesquisas sobre a emergência do ensino escolar da sociologia costumam sugerir o papel estratégico que a reforma do programa de ensino do Colégio Pedro II, em 1925, desempenhou no processo de tradução, de incorporação e de difusão do discurso sociológico — tal reforma seria ampliada para praticamente todos os currículos oficiais dos colégios secundários em 1931 (BRITO, 2012). Trata-se de um movimento ao mesmo tempo político e pedagógico que antecipou até mesmo a sua institucionalização nas universidades do país e marcou decisivamente alguns dos principais sentidos e significados que a disciplina pôde adquirir no período.

Naquele contexto, que se estendeu entre os anos de 1925 e 1942, o estabelecimento do conhecimento sociológico foi favorecido não apenas pelos ideais de racionalização, de nacionalização e de centralização administrativa, que figuraram como uma possibilidade de reformar a educação escolar, mas principalmente por representar os anseios de determinados setores das elites brasileiras em "decifrar" as contradiçóes de uma realidade social desigual e oferecer interpretaçóes capazes de conferir inteligibilidade ao processo de modernização do país (MEUCCI, 2011). Com a missão de proporcionar explicaçóes normativas a respeito da sociedade brasileira e de formar os futuros profissionais que teriam a tarefa de transformar a nação, a sociologia encontrou nessas instituiçóes escolares da primeira metade do século XX um ambiente propício para a difusão de perspectivas que acabariam se tornando uma herança clássica da disciplina no Brasil. 
Com o esgotamento do pacto oligárquico e dos discursos nacionalistas que sustentavam o Estado Novo, no entanto, a sociologia escolar não encontrou forças para se manter nos currículos do ensino secundário (MORAES, 2011). Uma agenda renovada para a área, então, passou a se organizar em meados da década de 1940 em torno de sua consolidação nas universidades brasileiras (FERNANDES, 1955). Formulada como uma maneira acadêmica de racionalizar o pensamento sobre o social e impulsionada pela criação de novos cursos de graduação e de pós-graduação em ciências sociais, a área rapidamente conquistou o status de especialidade científica engajada com a democratização e a modernização do país, desligando-se, assim, das antigas representaçóes escolares que a articulavam ao imaginário normativo e autoritário dos governos precedentes (MEUCCI, 2015).

Tal situação institucional, que nas décadas seguintes dividiu o campo discursivo da sociologia em antagonismos frequentes entre ensino e pesquisa, apenas foi rediscutida de forma mais abrangente pelos profissionais da área na passagem dos anos 1980 e 90 (MORAES, 2003) — um momento em que o processo de redemocratizaçáo do Estado brasileiro, atravessado pela gramática da cidadania e da inclusão, apresentou um ambiente novamente favorável ao retorno da disciplina aos bancos escolares. Nesse percurso recente, a Sociologia voltou a integrar os currículos da educação básica. Primeiramente, em 1997, tal qual conhecimento transversal aos conteúdos regulares da educação básica; posteriormente, em 2008, enquanto componente curricular obrigatório em todos os anos do ensino médio brasileiro.

Apesar das inúmeras disputas políticas e pedagógicos implicadas nas negociaçóes que reintroduziram a sociologia escolar, muitas devidamente documentadas pela literatura especializada da área, é significativo notar que o retorno da disciplina ao currículo coincidiu com transformaçóes mais gerais que impactaram toda a organização da educação pública nas últimas décadas. Isso porque, sob os ideais de democratizaçáo e de universalização da escolarização, uma nova concepção acerca da formação humana se estabeleceu com força nos discursos educacionais contemporâneos. Assim, atitudes relacionadas com o desenvolvimento da autonomia intelectual, do pensamento crítico e da pluralidade de perspectivas adquiriram destaque enquanto capacidades desejadas para as futuras geraçóes (MORAES, 2014).

Tais mudanças políticas que depositaram na escolarização pública muitas das esperanças pela "superação" da herança cultural deixada por mais de 20 anos de ditadura militar consolidaram as aspiraçóes por um Estado "mais abrangente", capaz de incluir novos sujeitos e novas experiências sociais na cena pública brasileira. Desse modo, os conhecimentos sociológicos, agora encarados como representantes dos desenvolvimentos das ciências sociais no país, assumiram lugar de destaque. Não mais por se comunicar com as elites dirigentes do país, como ocorreu nas primeiras décadas do século XX, mas por simbolizar, em grande medida, algumas das perspectivas sociopolíticas de coletivos que se organizaram mediante lutas diversas por justiça social e pela redemocratizaçáo do país. Tais coletivos atualmente concorrem 
para deslocar os eixos historicamente dominantes de interpretação do mundo social, tensionando as organizações escolares para torná-las mais abertas e sensíveis a outros saberes e demandas educacionais (GONH, 2016).

Em meio a esse movimento de ressignificação dos sistemas de ensino e de disputas pelo estabelecimento de um currículo escolar democrático, a sociologia estruturou-se enquanto um campo disciplinar relativamente autônomo no ensino médio, ampliando sensivelmente as possibilidades de circulação dos conhecimentos acadêmicos das ciências sociais no país. Abriu-se, assim, um cenário promissor de atuação profissional na educação pública que se fortaleceu ao longo da última década. Tal cenário vem se articulando em torno de transformaçôes recentes no perfil das licenciaturas (OLIVEIRA, 2016; LEAL, 2017), nos programas de fomento à docência (SANTOS, 2017), na produção de novos livros (MEUCCI, 2011) e materiais didáticos (BUENO \& CARNIEL, 2015), na elaboração de novas formas de ensinar e de aprender sociologia (TANGUY, 2012; CARNIEL \& RUGGI, 2015), bem como na consolidação de redes nacionais para o estudo do ensino de ciências sociais (SILVA, 2014).

Tais conquistas, no entanto, convivem atualmente com inúmeras críticas de diferentes setores da sociedade que colocam em dúvida a pertinência pedagógica dos conhecimentos produzidos pelas ciências sociais. As frequentes acusaçóes de "partidarizar" a compreensão da sociedade brasileira e de "incentivar" o debate de gênero e sexualidade em sala de aula são, provavelmente, os casos mais emblemáticos dessas reaçóes contrárias, os quais se notabilizaram, sobretudo, com a criação do movimento Escola sem Partido. Independentemente das razōes implicadas nessas perspectivas, parece significativo observar que elas expressam a existência de projetos de escolarização concorrentes que passaram a coconstituir-se como polaridades opostas em um embate político e educacional. De um lado, ficou a aposta na centralidade das disciplinas em um modelo escolar voltado à formação cidadã e ao estabelecimento de uma cultura científica; de outro, o projeto de regionalização das disciplinas em um currículo profissionalizante para o ensino médio brasileiro.

Diante desse cenário conflituoso, que se agravou com a publicação da Medida Provisória no 746, de 22 de outubro de 2016, alterando drasticamente a organização do ensino médio e retirando a obrigatoriedade de disciplinas como Sociologia e Filosofia, a questáo das dimensóes públicas do conhecimento produzido pela área parece retornar com força e suscitar uma agenda diversificada de pesquisas para a área. Afinal, o quanto efetivamente nos tornamos públicos? Onde, como e para quem divulgamos nossas pesquisas? De fato estamos dispostos a dialogar com audiências não especializadas? Ou nossos saberes estariam destinados a virar "peças de museu" na história da educação brasileira? Enfrentar tais desafios, que ultrapassam em muito os limites deste trabalho, quiçá signifique mais do que problematizar o imaginário cultural existente no Brasil sobre as ciências sociais. Talvez exija rediscutir o modo como nós mesmos imaginamos e nos relacionamos com públicos extra-acadêmicos. 


\section{Considerações finais}

Entre as diversas contribuiçōes que a sociologia escolar propiciou às sociologias acadêmicas e profissionais praticadas no Brasil, uma das mais evidentes está relacionada com a construção de formas de interlocução com públicos não acadêmicos - particularmente, o juvenil e que frequenta o ensino médio no país. Desse modo, para além de uma atividade didático-pedagógica, procuramos argumentar neste texto que a reflexão em torno dos sentidos e significados da sociologia enquanto disciplina escolar também constitui um exercício de sociologia pública. Afinal, a prática de ensino em sala de aula consiste em sistematizar estratégias de aprendizagem e em desenvolver metodologias para se comunicar com pessoas que não vão necessariamente se tornar especialistas. Nesse sentido, discutir o ensino de sociologia sob a perspectiva de sua interlocuçáo com públicos diversos nos parece ser um problema de investigação epistemológica e uma oportunidade de se compreender "a sociologia em ação" (CARNIEL \& RUGGI, 2015).

Por isso mesmo, enfrentar os desafios que envolvem a interlocução entre a ciência, o ensino e seus públicos representa uma maneira de contribuir para a construção de uma cultura científica compartilhada, ou ainda uma "cidadania sociologizada" (SANTOS, 2017; MORAES, 2009). Esse exercício sugere um fato aparentemente óbvio, mas nem sempre considerado em nossos meios acadêmicos: o envolvimento das pessoas com o pensamento sociológico representa uma oportunidade de romper com o isolamento e a burocratização dos discursos especializados. O debate sobre as dimensões públicas do ensino, portanto, não se limita a difundir os conhecimentos sociológicos numa linguagem clara e acessível aos estudantes. Refere-se, sobretudo, ao movimento de abertura para outras maneiras de produzir conhecimentos nas ciências sociais - com engajamentos e responsabilidades diferentes daquelas tradicionalmente esperadas nos meios universitários.

\section{Referências}

ALMEIDA, J.F. de. Velhos e novos aspectos da epistemologia das Ciências Sociais. Sociologia, Problemas e Práticas, Oeiras, n. 55, p. 11-24, set. 2007.

BECK, U. Como não se tornar uma peça de museu. Mediaçóes, Londrina, v. 15, n. 2, p. 16-27, jul./dez. 2010. http://dx.doi.org/10.5433/2176-6665.2010v15n2p16

BOURDIEU, P. Os usos sociais da ciência: por uma análise clínica do campo científico. São Paulo: Editora da Unesp, 2004.

BRAGA, R. Atravessando o abismo: uma sociologia pública para o ensino médio. In: BRAGA, R.; BURAWOY, M. Por uma sociologia pública. São Paulo: Alameda, 2009. p. 161-171.

BRITO, S.H.A. O ensino de sociologia e a organização do trabalho didático no Colégio Pedro II (1925-1945). Revista Brasileira de História da Educação, Campinas, v. 12, n. 3 (30), p. 95-124, set./dez. 2012. http://dx.doi.org/10.4322/rbhe.2013.005 
BUENO, Z. de P.; CARNIEL, F. Recursos livres, livros fechados: uma análise da dimensão interativa dos objetos educacionais digitais no ensino de Sociologia. Política \& Sociedade, Florianópolis, v. 14, n. 31, p. 132-154, set./dez. 2015. https://doi.org/10.5007/21757984.2015v14n31p132

BURAWOY, M. Meeting the challenges of Global Sociology. Global Dialogue, v. 1, n. 1, p. $1-2$, set. 2010 . Por uma sociologia pública. In: BRAGA, R.; BURAWOY, M. Por uma sociologia pública. São Paulo: Alameda, 2009. p. 15-66.

. Sociology as a combat sport. Current Sociology, Chicago, v. 62, n. 2, p. 140-155, mar. 2014. https://doi.org/10.1177/0011392113514713

- The promise of sociology: global challenges for national disciplines. Current Sociology, Chicago, v. 50, n. 5, p. 949-959, out. 2016. https://doi. org/10.1177/0038038516629901

CARNIEL, F; RUGGI, L.O. De sociólogo e de louco todo mundo tem um pouco: ou porque a sociologia é a disciplina mais legal da escola. Linhas, Florianópolis, v. 16, n. 31, p. 235-247, jan./abr. 2015. http://dx.doi.org/10.5965/1984723816302015235

DELICADO, Ana. Para que servem os museus científicos? Funçôes e finalidades dos espaços de musealização da ciência. In: CONGRESSO LUSO-AFRO-BRASILEIRO DE CIÊNCIAS SOCIAIS, 8., 2004. Anais... Coimbra, 2004. p. 1-17.

FERNANDES, F. Comunicação e debates. In: CONGRESSO BRASILEIRO DE SOCIOLOGIA, 1., 1995. Anais... São Paulo, 1955. p. 319-321.

FERNANDES, F. A sociologia como afirmação. In: IANNI, Octávio (Org.). Sociologia. São Paulo: Ática, 1986.

FOUCAULT, M. As palavras e as coisas: uma arqueologia das ciências humanas. São Paulo: Martins Fontes, 2010.

GONH, M. da G. Movimentos pela educação no Brasil. Crítica Educativa, Sorocaba, v. 2, n. 1, p. 9-20, jan./jun. 2016.

HANDFAS, A. O estado da arte da produção científica sobre o ensino de sociologia na educação básica. Revista Brasileira de Informação Bibliográfica em Ciências Sociais, Rio de Janeiro, v. 1, p. 45-61, 2014.

. O estado da arte do ensino de sociologia na educação básica: um levantamento preliminar da produção acadêmica. Inter-legere, Natal, n. 9, p. 386-400, 2011.

HEY, A.P.; RODRIGUES, L.S. Elites acadêmicas: as ciências sociais na Academia Brasileira de Ciências. Tempo Social, São Paulo, v. 29, n. 3, p. 9-33, 2017. http://dx.doi. org/10.11606/0103-2070.ts.2017.125964

KEINERT, F.C.; SILVA, D.P. A gênese da ciência política Brasileira. Tempo Social, São Paulo, v. 22, n. 1, p. 79-98, 2010. http://dx.doi.org/10.1590/S0103-20702010000100005

LEAL, S. de A.G. Dispositivos de normatização do ensino de sociologia: formação e saberes docentes de licenciandos em Ciências Sociais no Distrito Federal. Educação \& Sociedade, Campinas, 2017. http://dx.doi.org/10.1590/es0101-73302017151279 
LUZ, M.; SABINO, C.; MATTOS, R. A ciência como cultura do mundo contemporâneo: a utopia dos saberes das (bio) ciências e a construçáo midiática do imaginário social. Sociologias, v. 15, n. 32, p. 236-254, jan./abr. 2013. http://dx.doi.org/10.1590/S1517$\underline{45222013000100010}$

LUZ, M.; SABINO, C.; MATTOS, R.S.; FERLA, A.A.; ANDRES, B.; ALBA, R.D.; MACHADO, A.S.; ASSIMOS, R. Contribution towards studying the contemporary social imaginary: rhetoric and images of biosciences in popular scientific periodicals. Interface, Botucatu, v. 17, n. 47, p. 901-912, out./dez. 2013. http://dx.doi.org/10.1590/1807$\underline{57622013.0661}$

MARQUES, L.R. Democracia radical e democracia participativa: contribuiçôes teóricas à análise da democracia na educação. Educação \& Sociedade, Campinas, v. 29, n. 102, p. 5578, abr. 2008. http://dx.doi.org/10.1590/S0101-73302008000100004

MELLO, L. Prática de pesquisa e "Sociologia pública": uma discussão em torno de diálogos possíveis, outros nem tanto. Sociologias, Porto Alegre, ano. 11, n. 22, p. 76-99, jul./dez. 2009.

MEUCCI, S. Institucionalizaçâo da sociologia no Brasil: primeiros manuais e cursos. São Paulo: Hucitec, 2011.

. Notas sobre o pensamento social brasileiro nos livros didáticos de sociologia. Revista Brasileira de Ciências Sociais, SBS, v. 2, n. 3, p. 209-232, jan./jun. 2014. http:// dx.doi.org/10.20336/rbs.70

. Sociologia na educação básica no Brasil: um balanço da experiência remota e recente. Ciências Sociais Unisinos, São Leopoldo, v. 51, n. 3, p. 251-260, set./dez. 2015. http://dx.doi.org/10.4013/csu.2015.51.3.02

MORAES, A.C. de. Ciência e ideologia na prática dos professores de Sociologia no ensino médio: da neutralidade impossível ao engajamento indesejável, ou seria o inverso? Educação \& Realidade, Porto Alegre, v. 39, n. 1, p. 17-38, jan./mar. 2014. http://dx.doi. org/10.1590/S2175-62362014000100003

. Ensino de Sociologia: periodização e campanha pela obrigatoriedade. Caderno Cedes, Campinas, v. 31, n. 85, p. 359-382, set./dez. 2011.

. Licenciatura em Ciências Sociais e ensino de Sociologia: entre o relato e o balanço. Tempo Social, São Paulo, v. 15, n. 1, p. 5-20, jan./maio 2003. http://dx.doi.org/10.1590/ $\underline{\text { S0103-20702003000100001 }}$

MORAES, L.B.P. de. Representando disputas, disputando representaçóes: cientistas sociais e campo acadêmico no ensino de sociologia. Dissertação (Mestrado em Ciências Sociais) Universidade Estadual Paulista "Júlio de Mesquita Filho", Araraquara, 2016.

MORAES, L.F. Da sociologia cidadã à cidadania sociológica: as tensóes e disputas na construção dos significados de cidadania e do ensino de Sociologia. Dissertação (Mestrado em Sociologia)-Universidade Federal do Paraná, Curitiba, 2009.

OLIVEIRA, A. A formação de professores de sociologia na região Norte: configuraçôes e tendências. Novos Cadernos NAEA, Belém, v. 19, n. 1, p. 253-274, jan./abr. 2016. http:// dx.doi.org/10.5801/ncn.v19i1.1898 
PERLATTO, F. A imaginação sociológica brasileira: a sociologia no Brasil e sua vocação pública. Curitiba: CRV, 2016.

Sociologia pública e o Brasil: apontamentos para um debate. Revista de Ciências Humanas, Florianópolis, v. 10, n. 2, p. 256-268, jul./dez. 2010.

PERLATTO, F; MAIA, J.M. Qual sociologia pública? Uma visão a partir da periferia. Lua Nova, São Paulo, n. 87, p. 83-112, 2012. http://dx.doi.org/10.1590/S0102$\underline{64452012000300005}$

REIS, E.P.; REIS, F.W.; VELHO, G. As ciências sociais nos últimos 20 anos: três perspectivas. Revista Brasileira de Ciências Sociais, São Paulo, v. 12, n. 35, 1997. http:// dx.doi.org/10.1590/S0102-69091997000300002

SANTOS, M.B. O Pibid na área de ciências sociais: da formação do sociólogo à formação do professor de sociologia. Tese (Doutorado em Sociologia)-Universidade Federal de Brasília, Brasília, 2017.

SCHWARTZMAN, S. A sociologia como profissão pública no Brasil. Cadernos $C R H$, Salvador, v. 22, n. 56, p. 271-279, maio/ago. 2009. http://dx.doi.org/10.1590/S0103$\underline{49792009000200005}$

SIEBEL, C.; SMITH, K.C. How public are we? Coverage of sociology by the Associated Press. American Sociologist, n. 40, p. 289-308, set. 2009. http://dx.doi.org/10.1007/ $\underline{\text { s12108-009-9075-0 }}$

SILVA, I.F. A sociologia de volta à escola: um balanço provisório. Revista de Ciências Sociais, Fortaleza, v. 45, n. 1, p. 277-284, jan./jun. 2014.

TANGUY, L. A sociologia: ciência e ofício. Educação \& Sociedade, Campinas, v. 33, n. 118, p. 33-46, mar. 2012.

TURNER, J.H. Contra a sociologia pública: será ela a melhor forma de tornar a Sociologia relevante? Caderno CRH, Salvador, v. 22, n. 56, p. 255-269, maio/ago. 2009. http://dx.doi.org/10.1590/S0103-49792009000200004

WILLIAMS, R. Marxismo e literatura. Rio de Janeiro: Zahar, 1979.

Recebido em 04 de outubro de 2017.

Aceito em 30 de abril de 2018. 